DOI: 10.4274/ejgg.galenos.2021.450

Eur J Geriatr Gerontol 2021;3(3):143-148

\title{
Relationship Between Neutrophil-lymphocyte Ratio and Malnutrition in Older Adults
}

\author{
(D) Bilge Müge Gökçekuyu1, (1) Sibel Akın1, (1) Firuzan Fırat Özer1, (1) Tuba Soysal1', (1) Nurdan Şentürk Durmuş1, \\ (D) Gözde Ertürk Zararsız² \\ 1 Erciyes University Faculty of Medicine, Department of Internal Medicine, Clinic of Geriatrics, Kayseri, Turkey \\ 2Erciyes University Faculty of Medicine, Department of Biostatistics, Kayseri, Turkey
}

\section{Abstract}

Objective: Blood neutrophil-lymphocyte ratio (NLR) indicated an increased inflammation in cardiac, rheumatologic, cancer, and some geriatric syndromes. This study aimed to determine the diagnostic value of NLR in the diagnosis of malnutrition or severity.

Materials and Methods: A total of 303 elderly patients were included in this study. A comprehensive geriatric assessment was performed on each patient, and the mini nutritional assessment tool was used to assess the nutritional status. The hemogram values of all patients were investigated to determine an NLR inflammatory marker.

Results: Logistic regression analysis showed that the presence and risk of malnutrition were independently associated with NLR, hemoglobin, hematocrit, albumin, age, and smoking in univariate analysis. Of the above independent variables, body mass index, hematocrit, and vitamin B12 were found to be significantly associated with malnutrition and risk of malnutrition in multivariate analysis. This study revealed that patients with malnutrition and those at risk of malnutrition have elevated NLR than those with normal nutritional status. However, it was not significantly associated with multivariate analysis.

Conclusion: A variety of etiological factors and mild or severe inflammation in the course of concomitant diseases cannot be overlooked in the current state of patients. Therefore, laboratory or clinical criteria other than the NLR would be useful for early detection of the relationship between malnutrition and inflammation.

Keywords: Blood neutrophil-lymphocyte ratio, malnutrition, older adult, inflammation

\section{Introduction}

Malnutrition (MN) is defined as a change in body composition (decrease in lean body mass) and a decrease in body mass due to a decrease in the intake of nutrients and deterioration in physical and mental functions and clinical results. MN may be the result of hunger and/or disease and/or aging. These factors that adversely affect the nutritional status in the elderly include physiological changes associated with aging, acute and chronic diseases, dental and oral health problems, polypharmacy, economic problems, inability to shop alone, inability to prepare food, and problems with eating. Unfortunately, this geriatric syndrome, which is not recognized or cared enough for by many clinicians and is not uncommon, has many negative consequences such as impaired functionality, increased morbidity and mortality risk $(1,2)$.

Many malnourished patients have disease-related inflammation, and the presence of inflammation affects both requirements and food intake. As a result, with the development of inflammation, anorexia is induced and muscle catabolism and resting energy consumption increase (3). The global leadership initiative on MN recommends that the presence of severe disease/inflammation has a vital role to play in both etiological criteria and screening tests (4). Primary infections, burns, and closed head trauma are often associated with severe acute inflammation. It is often

Address for Correspondence: Bilge Müge Gökçekuyu, Erciyes University Faculty of Medicine, Department of Internal Medicine, Clinic of Geriatrics, Kayseri, Turkey

E-mail: bilgemgondiken@gmail.com ORCID: orcid.org/0000-0002-7470-5810

Received: 08.11.2020 Accepted: 08.01.2021

Cite this article as: Gökçekuyu BM, Akın S, Fırat Özer F, Soysal T, Şentürk Durmuş N, Ertürk Zararsız G. Relationship Between Neutrophil-lymphocyte Ratio and Malnutrition in Older Adults. Eur J Geriatr Gerontol 2021;3(3):143-148

๑Copyright 2021 by the Academic Geriatrics Society / European Journal of Geriatrics and Gerontology published by Galenos Publishing House. 
observed with fever, negative nitrogen balance, and increased resting energy consumption. There is also a mild to moderate chronic or recurrent inflammation in chronic organ failures, such as heart failure, chronic liver, kidney failure, or chronic obstructive pulmonary disease, and rheumatoid arthritis. In severe inflammation, the diagnosis and decision-making process is easily passed, whereas in less severe cases, laboratory-based biomarkers are needed. C-reactive protein (CRP), erythrocyte sedimentation rate, albumin or pre-albumin are commonly used today.

Blood neutrophil-lymphocyte ratio (NLR) is a new, cheap, and easily measurable marker of inflammation. In cardiac diseases, rheumatologic diseases, and cancers and some geriatric syndromes such as frailty, sarcopenia, and Alzheimer's disease (AD), NLR has been shown to indicate an increase in inflammation, or it is associated with severity or mortality in the related disease. In this case, the use of practical, inexpensive, laboratory-based biomarkers that will draw the clinician's attention will become increasingly important.

The present study aims to determine whether the NLR has a diagnostic value in the diagnosis or severity of MN.

\section{Materials and Methods}

Three hundred and three patients aged sixty years and over who were admitted to the geriatric medicine outpatient clinic of our hospital for medical care for any reason were enrolled in this cross-sectional study. Participants aged 60 and over who had a detailed geriatric evaluation and did not meet the following exclusion criteria were included in the study. Exclusion criteria were: Those with known immune origin or rheumatologic disease; those with high clinical suspicion and research in terms of rheumatologic disease; those who received immunosuppressive treatment; those who received systemic medication with steroid for any reason, and those who had active or not cured cancer history and acute infection. Patient information including age, sex, smoking, height, weight, number of chronic diseases including dementia and depression, and prescribed drugs, whether they were using enteral nutrition products in the last six months, was collected. Body mass index (BMI) was calculated using weight $(\mathrm{kg}) /$ height squared $\left(\mathrm{m}^{2}\right)$. Nutritional status was assessed by the mini nutritional assessment (MNA). MNA is suitable for both elderly outpatients and inpatients and also for nursing homes. According to this scale; if the individual's score is $\geq 24$ it is considered as wellnourished (WN), $<17$ is considered as MN, between 17 and 23.5 is considered as malnutrition risk (MNR) (5). Frailty was assessed by the FRAIL scale (fatigue, resistance, ambulation, illnesses and loss of weight). According to the FRAIL scale, $\geq 3$ points frail, 1-2 points pre-frail, 0 points are considered to be robust (6). The screening tool used for the evaluation of dysphagia risk was the 10-item eating assessment tool (7). A score of $\geq 3$ in the EAT-10 dysphagia screening test is interpreted as abnormal in terms of dysphagia. The SARC-F questionnaire was developed as a rapid diagnostic tool for sarcopenia. SARC-F survey is an inexpensive, easy and short screening test developed for sarcopenia screening. A score of $\geq 4$ as a result of this test is considered abnormal and clinically associated with poor outcomes associated with sarcopenia (8). Geriatric depression was assessed by the geriatric depression scale-30 questionnaire; 14 points are accepted in favor of depression with high sensitivity and high specificity (9). The mini-mental state assessment test was applied to the patients; $\leq 23$ score is most often described as abnormal and is considered an indicator of cognitive impairment $(10,11)$. The hemogram $(\mathrm{CBC})$ values of all patients were investigated to determine NLR. Blood count analysis was performed with the Sysmex XN-9000 automated hematology system (Kobe, Japan). The neutrophil and lymphocyte counts were recorded in units of $10^{3} / \mu \mathrm{L}$ and were proportioned. Patients with elevated isolated CRP as a result of further investigations were not excluded. Informed consent was obtained from all the participants. The study was approved by the Local Ethics Committee (2019/136, 20.02.2019).

\section{Statistics}

Histogram, q-q plots, and Shapiro-Wilk's test were applied to assess data normality. Descriptive statistics of categorical data are given as $\mathrm{n}$ and percentage, while descriptive of countinous variables are given as mean, median, standard deviation and 2575. percentile values. The relationship between the categorical variables with each other was tested by Exact method of Pearson chi-square test statistics, and Bonferroni test statistics corrected Dunn test were used to multiple comparison test in categorical variables. The mean comparison between more than two independent groups was evaluated in One-Way ANOVA and Kruscal-Wallis test statistics. Levene test was used to assess variance homogeneity, while multiple group comparison analyzes were performed with Bonferonni test statistic. The risk factors were investigated between the individuals with and without MN according to the blood parameters examined and the demographic characteristics of the patient. Binary logistic regressions, with results reported as odds ratios (OR) and 95\% confidence intervals (CI). Furthermore, univariate and multivariate logistic regression analysis were used to determine the most significant risk factors. Significant variables at $p<0.25$ on univariate analysis were taken into multiple model and forward stepwise selection was performed using likelihood ratio statistic at $p<0.10$ stringency level. $O R$ were also given with $95 \% \mathrm{Cl}$. Hosmer Lemeshow test statistics used to goodness of fit test for testing model instability. Analyses were conducted using TURCOSA TURCOSA (Turcosa Analytics Ltd. Co., Turkey, https://turcosa.com.tr/) software. A p-value less than 5\% was considered statistically significant. 


\section{Results}

We included 303 older adults whose mean age was 71.00 (66.00-78.00), of which 63.8\% were females, and 36.3\% were males. According to MNA, it was found that 40 participants (13.2\%) were malnourished (MN), and 125 participants $(41.2 \%)$ were at risk of MNR while 138 participants (45.5\%) were WN. Analyzes were made separately for each of the groups (MN, MNR, WN) in order to better determine the relationship between demographic data, laboratory values and clinical characteristics with nutritional status. It was found that MN rates were found to increase in advanced age in both genders $(p<0.001)$. Table 1 shows that there were significant differences in age $(p<0.001)$, female gender $(p=0.047)$, BMI $(p<0.001)$, hemoglobin $(p<0.001)$, hydrochlorothiazide $(p<0.001)$, total protein $(p<0.001)$, albumin $(p<0.001), B 12 \quad(p<0.001)$, and folic acid $(p<0.001)$ findings between WN and MNR and MN participiants. The characteristics of the participants and laboratory are given in Table 1 . The clinic and comorbid features of WN, MNR, and MN participiants are given in Table 2. This shows the significant differences in chronic diseases and geriatric syndromes; polypharmacy ( $\geq 4$ drugs) $(p=0.046)$, urinary incontinence $(p<0.001)$, dementia $(p<0.001)$, depression $(p<0.001)$, dysphagia $(p<0.001)$, SARC-F $(\geq 4)$ $(p<0.001)$, and frail older adults $(p<0.001)$. Logistic regression analyses were performed to identify independent risk factors over nutritional status. At this stage of the statistical analysis; In order to capture the possible significance or relationship between NLR and MN level, MN and MNR were accepted as a group, while WN was accepted as a separate group. The poor nutritional status was defined as a combination of MN and MNR. Patients were divided into two groups, with an MNA score of $\leq 23.5$ and those with $>24$. Logistic regression analysis showed that the presence of poor nutritional status was independently associated with NLR, Hb, HCT, albumin, age, smoking in

\begin{tabular}{|c|c|c|c|c|c|}
\hline Variable & $\begin{array}{l}\text { Total } \\
(n=303)\end{array}$ & $\begin{array}{l}\text { MNR (17-23.5) } \\
(n=125)\end{array}$ & $\begin{array}{l}\text { MN }(<17) \\
(n=40)\end{array}$ & $\begin{array}{l}\text { WN }(\geq 24) \\
(n=138)\end{array}$ & $\mathbf{p}$ \\
\hline Gender, female & $193(63.7)$ & $80(64.0)^{\mathrm{a}}$ & $32(80.0)^{b}$ & $81(58.7)^{a}$ & 0.047 \\
\hline $\begin{array}{l}\text { Smoking status } \\
\text { Ex smoker } \\
\text { Current smoker } \\
\text { Non-smoker }\end{array}$ & \begin{tabular}{|l}
$38(14.1)$ \\
$24(8.9)$ \\
$208(77.0)$ \\
\end{tabular} & $\begin{array}{l}11(10.2) \\
12(11.1) \\
85(78.7)\end{array}$ & $\begin{array}{l}3(9.4) \\
4(12.5) \\
25(78.1)\end{array}$ & $\begin{array}{l}24(18.5) \\
8(6.2) \\
98(75.4)\end{array}$ & 0.223 \\
\hline BMI $\left(\mathrm{kg} / \mathrm{cm}^{2}\right)$ & 28.7 (24.4-33.6) & $28.9(24.3-34.4)^{\mathrm{a}}$ & $24.2(22.0-28.1)^{b}$ & $30.1(26.2-33.8)^{\mathrm{a}}$ & $<0.001$ \\
\hline NLR & $2.0(1.6-2.8)$ & $2.1(1.5-3.0)$ & $2.3(1.8-3.2)$ & $2.0(1.5-2.7)$ & 0.092 \\
\hline CRP (mg/dL) & $2.7(1.4-4.8)$ & $2.4(1.3-4.9)$ & $2.9(1.2-6.1)$ & $2.9(1.5-4.5)$ & 0.780 \\
\hline $\mathrm{Hb}(\mathrm{g} / \mathrm{dL})$ & $13.9 \pm 1.7$ & $13.8 \pm 1.7^{a}$ & $12.8 \pm 1.80^{b}$ & $14.4 \pm 2.8^{c}$ & $<0.001$ \\
\hline Glu (mg/dL) & $103.0(90.0-128.0)$ & $108.0(90.0-128.0)$ & $97.0(86.0-120.0)$ & $103.0(92.0-134.8)$ & 0.101 \\
\hline GFR (mL/min) & $74.2(61.1-87.5)$ & 73.6 (59.7-87.2) & $70.4(53.1-88.4)$ & 76.2 (65.0-87.8) & 0.316 \\
\hline Uric acid $(\mathrm{mg} / \mathrm{dL})$ & $5.2(4.3-6.2)$ & $5.1(4.3-6.0)$ & $5.0(3.7-6.3)$ & $5.4(4.8-6.4)$ & 0.341 \\
\hline TG (mg/dL) & $159.2 \pm 83.3$ & $157.2 \pm 81.0$ & $140.3 \pm 66.0$ & $165.9 \pm 88.9$ & 0.278 \\
\hline LDL (mg/dL) & $118.7 \pm 36.1$ & $115.6 \pm 37.1$ & $115.3 \pm 37.5$ & $122.2 \pm 34.8$ & 0.319 \\
\hline HDL (mg/dL) & 49.5 (41.0-58.0) & $49.0(40.0-57.0)$ & $52.0(40.6-61.0)$ & $49.9(41.0-59.0)$ & 0.845 \\
\hline Total protein $(\mathrm{g} / \mathrm{dL})$ & $7.3(7.0-7.6)$ & $7.3(7.0-7.6)^{\mathrm{a}}$ & $7.0(6.7-7.6)^{\mathrm{ab}}$ & $7.3(7.0-7.7)^{\mathrm{b}}$ & 0.032 \\
\hline Albumin (g/dL) & $4.6 \pm 0.4$ & $4.5 \pm 0.4^{\mathrm{a}}$ & $4.3 \pm 0.4^{b}$ & $4.7 \pm 0.3^{b}$ & $<0.001$ \\
\hline
\end{tabular}


univariate analysis. Of the above independent variables, BMI, HCT, B12 were found to be significantly associated with poor nutritional status in multivariate analysis (Table 3). The present study found that patients with MN and those at risk of MN have elevated NLR in comparison with normal nutritional status but was not found to be significantly associated in multivariate analysis.

\section{Discussion}

The present study found that older adults that are $\mathrm{MN}$ and at MN risk have elevated NLR in comparison with normal nutritional status but were not found to be significantly associated with multivariate analysis. Inflammaging is a chronic low-grade inflammation -increased pro-inflammatory cytokines that are commonly observed during aging (12). Additionality, chronic inflammation is associated- with many age-related chronic disorders such as atherosclerosis, diabetes, obesity, sarcopenia, and $A D$ (13). Inflammation contributes to $M N$ through altered metabolism with increased anorexia and reduced food intake, as well as increased resting energy expenditure and increased muscle catabolism. Notably, the appetite may be reduced due to acute and chronic diseases associated with inflammation (cancer, chronic obstructive pulmonary disease, heart failure) or during the treatment process of diseases such as drug treatment, surgery.

On the other hand, psychosocial problems such as depression, loneliness, and loss of spouses are the factors that cause decreased appetite. Cachexia can be a severe cause of MN. It may develop as a result of $\mathrm{MN}$, is mediated by pro-inflammatory cytokines, and has long been associated with several chronic conditions (14). Derman et al. (15) showed that baseline weight and NLR were inversely related, and weight change (loss or gaining) and NLR were inversely related at 12 weeks. In this study, longitudinal measurements of weight and NLR were also negatively associated (15). Another study demonstrated that the NLR is a useful marker of MN and it was significantly inversely correlated with serum levels of prealbumin and retinol-binding protein in stage IV gastric cancer (16). These studies were carried out with cancer patients. However, we evaluated the relationship between NLR and MN in older adults without inflammation. To our knowledge, the present study is the first study to demonstrate the NLR an association between with MN. The role of inflammation and oxidative stress in the pathogenesis of cardiovascular disease is well known. Therefore, the importance of relevant biomarkers has been emphasized frequently (17). In another study by Gibson et al. (18), it was found that NLR increase in pre-operative and post-operative period was closely related to the development of atrial fibrillation. Increased NLR was found to be associated with long-term mortality in patients with unstable angina and non-ST elevation myocardial infarction (19). The NLR is in the literature in determining the severity of cardiovascular disease and is accepted as a cheap, easy and clinically relevant marker in this regard (20). In another study with 255 ulcerative colitis and control group, attention was drawn to the close association of NLR with disease activity

\begin{tabular}{|c|c|c|c|c|c|}
\hline Variable & $\begin{array}{l}\text { Total } \\
(n=303)\end{array}$ & $\begin{array}{l}\text { MNR (17-23.5) } \\
(n=125)\end{array}$ & $\begin{array}{l}\mathrm{MN}(<17) \\
(n=40)\end{array}$ & $\begin{array}{l}\text { WN }(\geq 24) \\
(n=138)\end{array}$ & p \\
\hline $\begin{array}{l}\text { Drug } \\
<4 \\
\geq 4\end{array}$ & $\begin{array}{l}123(42.0) \\
170(58.0)\end{array}$ & $\begin{array}{l}49(40.8) \\
71(59.2)\end{array}$ & $\begin{array}{l}10(25.6) \\
29(74.4)\end{array}$ & $\begin{array}{l}64(47.8) \\
70(52.2)\end{array}$ & 0.046 \\
\hline $\mathrm{UI}$ & $132(46.2)$ & 56 (47.5) & $26(72.2)$ & 50 (37.9) & 0.001 \\
\hline HT & $217(72.1)$ & $88(70.4)$ & $29(74.4)$ & $100(73.0)$ & 0.847 \\
\hline DM & $122(40.5)$ & $53(42.4)$ & $10(25.6)$ & $59(43.1)$ & 0.127 \\
\hline CAD & $68(22.7)$ & $36(29.0)$ & $10(25.6)$ & 22 (16.1) & 0.039 \\
\hline Dementia & $42(14.0)$ & $19(15.4)$ & $16(40.0)$ & $7(5.1)$ & $<0.001$ \\
\hline Depression & $158(53.2)$ & $77(62.1)$ & 33 (84.6) & 48 (35.8) & $<0.001$ \\
\hline Dysphagia & $62(21.2)$ & $38(31.4)$ & $16(45.7)$ & $8(5.9)$ & $<0.001$ \\
\hline ONS & $14(4.7)$ & $6(4.8)$ & $4(10.3)$ & $4(2.9)$ & 0.158 \\
\hline $\begin{array}{l}\text { Sarc-F } \\
<4 \\
\geq 4\end{array}$ & $\begin{array}{l}171(57.8) \\
125(42.2)\end{array}$ & $\begin{array}{l}56(46.3) \\
65(53.7)\end{array}$ & $\begin{array}{l}7(18.4) \\
31(81.6)\end{array}$ & $\begin{array}{l}108(78.8) \\
29(21.2)\end{array}$ & $<0.001$ \\
\hline $\begin{array}{l}\text { FRAIL scale } \\
\text { Robust } \\
\text { Prefrail } \\
\text { Frail }\end{array}$ & $\begin{array}{l}47(15.9) \\
165(55.7) \\
84(28.4)\end{array}$ & $\begin{array}{l}12(9.8) \\
70(57.4) \\
40(32.8)\end{array}$ & $\begin{array}{l}0(0) \\
12(32.4) \\
25(67.9)\end{array}$ & $\begin{array}{l}35(25.5) \\
83(60.6) \\
19(13.9)\end{array}$ & $<0.001$ \\
\hline
\end{tabular}




\begin{tabular}{|c|c|c|c|c|}
\hline \multirow[b]{2}{*}{ Variable } & \multicolumn{2}{|l|}{ Univariate } & \multicolumn{2}{|l|}{ Multivariate } \\
\hline & OR (95\% Cl) & p & OR $(95 \% \mathrm{Cl})$ & $\mathbf{p}$ \\
\hline Age (years) & $1.05(1.02-1.08)$ & 0.002 & - & - \\
\hline Gender, female & $1.49(0.93-2.38)$ & 0.099 & - & - \\
\hline \begin{tabular}{|l} 
Smoking status \\
Current smoker \\
Ex smoker \\
Non-smoker \\
\end{tabular} & \begin{tabular}{|l}
1.00 \\
$0.29(0.10-0.85)$ \\
$0.56(0.23-1.37)$ \\
\end{tabular} & $\begin{array}{l}- \\
0.025 \\
0.561\end{array}$ & - & - \\
\hline BMI & $0.95(0.91-0.99)$ & 0.010 & $0.88(0.80-0.97)$ & 0.007 \\
\hline NLR & $1.22(1.01-1.47)$ & 0.038 & - & - \\
\hline CRP (mg/dL) & $1.04(0.96-1.12)$ & 0.324 & - & - \\
\hline $\mathrm{Hb}(\mathrm{g} / \mathrm{dL})$ & $1.01(0.99-1.02)$ & 0.559 & - & - \\
\hline HTC & $0.89(0.84-0.94)$ & $<0.001$ & $0.90(0.80-1.01)$ & 0.082 \\
\hline WBC $(\mu \mathrm{L})$ & $1.05(0.93-1.19)$ & 0.413 & - & - \\
\hline PLT $(\mu \mathrm{L})$ & $1.00(1.00-1.0)$ & 0.089 & - & - \\
\hline Glu (mg/dL) & 0.99 (0.99-1.00) & 0.239 & - & - \\
\hline GFR (mL/dk) & 0.99 (0.98-1.00) & 0.061 & - & - \\
\hline Uric acid $(\mathrm{mg} / \mathrm{dL})$ & $0.88(0.72-1.07)$ & 0.187 & - & - \\
\hline TG (mg/dL) & 0.99 (0.99-1.00) & 0.219 & - & - \\
\hline LDL (mg/dL) & 0.99 (0.99-1.00) & 0.131 & - & - \\
\hline HDL (mg/dL) & $1.00(0.99-1.02)$ & 0.813 & - & - \\
\hline Total protein (g/dL) & $0.68(0.43-1.08)$ & 0.678 & - & - \\
\hline Albumin (g/dL) & $0.27(0.13-0.54)$ & $<0.001$ & - & - \\
\hline ALT (U/L) & $0.99(0.97-1.00)$ & 0.194 & - & - \\
\hline B12 (pg/mL) & $1.00(1.00-1.00)$ & 0.011 & $1.00(1.00-1.01)$ & 0.071 \\
\hline Folic acid $(\mathrm{mg} / \mathrm{dL})$ & $0.94(0.87-1.01)$ & 0.088 & - & - \\
\hline Vitamin D & $1.00(0.98-1.02)$ & 0.973 & - & - \\
\hline PTH (pg/mL) & 0.99 (0.99-1.00) & 0.476 & - & - \\
\hline
\end{tabular}

(21). In a study of 399 diabetic and control subjects, the NLR was found to be higher in patients with diabetes but was also correlated with the presence of simultaneous microvascular complications (22).

A study including 817 older adults in Turkey showed a significant relationship between inflammation and frailty (23). In a study of 416 older adults, including AD and control group, higher NLR rates were found in the $A D$ group compared to healthy controls. The role of the inflammatory process in the pathogenesis of $A D$ has been emphasized (24). In light of this information in the literature, the NLR rate has been accepted as an indicator of inflammation for many diseases and geriatric syndromes. One reason for the lack of a significant relationship between MN and NLR in this study is that MN may develop due to multiple etiologic factors or as a result of one or more geriatric syndromes such as frailty, sarcopenia, and AD. The association of these syndromes with the inflammatory process is well known. Also, it is difficult to say that the current outcome, whether there is any possible relationship between MN/MNR and NLR is not entirely independent of the effects of frailty, sarcopenia, and AD. Significant increases in NLR may already be expected in diseases such as diabetes mellitus, coronary artery disease or activation of any chronic immune disease with moderate to severe inflammatory processes. The exclusion criteria in this study excluded the evident inflammatory processes or processes that may contribute to the increase in CRP. Therefore, exclusion criteria were applied very strictly to minimize the margin of error. One of the limited aspects of the study is the exclusion of as many as obvious inflammatory causes, which may constitute a significant portion of the etiologic causes. In this case, the relationship between MN/MNR and NLR may not be well reflected since it is difficult to know to what extent the MN/ MNR contains inflammation on a case-by-case basis. 


\section{Conclusion}

As mentioned above, the etiology of MN includes reduced food intake or decreased food absorption, or an acute event/injuryrelated or chronic disease-related inflammatory condition. A variety of etiological factors and mild or severe inflammation in the course of concomitant diseases cannot be overlooked in the current state of patients. Accordingly, it would be useful to find other laboratory or clinical criteria other than NLR in order to detect early the relationship between MN and inflammation.

\section{Ethics}

Ethics Committee Approval: The study was approved by the Local Ethics Committee (2019/136, 20.02.2019).

Informed Consent: Informed consent was obtained from all the participants.

Peer-review: Externally and internally peer-reviewed.

\section{Authorship Contributions}

Surgical and Medical Practices: B.M.G., S.A., F.F.Ö., T.S., N.S..D., Concept: B.M.G., S.A., F.F.Ö., T.S., N.Ş.D., G.E.Z., Design: B.M.G., S.A., F.F.Ö., T.S., N.S..D., G.E.Z., Data Collection or Processing: B.M.G., S.A., F.F.Ö., T.S., N.Ş.D., Analysis or Interpretation: S.A., G.E.Z., Literature Search: B.M.G., S.A., G.E.Z., Writing: B.M.G., S.A., G.E.Z.

Conflict of Interest: No conflict of interest was declared by the authors.

Financial Disclosure: The authors declared that this study received no financial support.

\section{References}

1. Wallace JI, Schwartz RS, LaCroix AZ, Uhlmann RF, Pearlman RA. Involuntary weight loss in older outpatients: incidence and clinical significance. J Am Geriatr Soc 1995;43:329-337.

2. Morley JE. Pathophysiology of anorexia. Clin Geriatr Med 2002;18:661-673.

3. Jensen GL. Malnutrition and inflammation-"burning down the house": inflammation as an adaptive physiologic response versus self-destruction? JPEN J Parenter Enteral Nutr 2015;39:56-62.

4. Cederholm $\mathrm{T}$, Jensen GL, Correia MITD, Gonzalez MC, Fukushima $R$, Higashiguchi T, Baptista G, Barazzoni R, Blaauw R, Coats AJS, Crivelli AN, Evans DC, Gramlich L, Fuchs-Tarlovsky V, Keller H, Llido L, Malone A, Mogensen KM, Morley JE, Muscaritoli M, Nyulasi I, Pirlich M, Pisprasert $V$, de van der Schueren MAE, Siltharm S, Singer $P$, Tappenden $K$, Velasco N, Waitzberg D, Yamwong P, Yu J, Van Gossum A, Compher C; GLIM Core Leadership Committee, GLIM Working Group. GLIM criteria for the diagnosis of malnutrition - A consensus report from the global clinical nutrition community. J Cachexia Sarcopenia Muscle 2019;10:207-217.

5. Vellas B, Guigoz Y, Garry PJ, Nourhashemi F, Bennahum D, Lauque S, Albarede JL. The Mini Nutritional Assessment (MNA) and its use in grading the nutritional state of elderly patients. Nutrition 1999;15:116-122.

6. Woo J, Yu R, Wong M, Yeung F, Wong M, Lum C. Frailty Screening in the Community Using the FRAIL Scale. J Am Med Dir Assoc 2015;16:412-419.
7. Belafsky PC, Mouadeb DA, Rees CJ, Pryor JC, Postma GN, Allen J, Leonard RJ. Validity and reliability of the Eating Assessment Tool (EAT-10). Ann Otol Rhinol Laryngol 2008;117:919-924.

8. Malmstrom TK, Miller DK, Simonsick EM, Ferrucci L, Morley JE. SARC-F: a symptom score to predict persons with sarcopenia at risk for poor functional outcomes. J Cachexia Sarcopenia Muscle 2016;7:28-36.

9. Yesavage JA, Brink TL, Rose $T L$, Lum 0 , Huang $V$, Adey $M$, Leirer VO. Development and validation of a geriatric depression screening scale: a preliminary report. J Psychiatr Res 1982-1983;17:37-49.

10. Folstein MF, Folstein SE, McHugh PR. "Mini-mental state". A practical method for grading the cognitive state of patients for the clinician. J Psychiatr Res 1975;12:189-198.

11. Tsoi KK, Chan JY, Hirai HW, Wong SY, Kwok TC. Cognitive Tests to Detect Dementia: A Systematic Review and Meta-analysis. JAMA Intern Med 2015;175:1450-1458.

12. Franceschi $\mathrm{C}$, Campisi J. Chronic inflammation (inflammaging) and its potential contribution to age-associated diseases. J Gerontol A Biol Sci Med Sci 2014;69(Suppl 1):S4-9.

13. Chung HY, Lee EK, Choi YJ, Kim JM, Kim DH, Zou Y, Kim CH, Lee J, Kim HS, Kim ND, Jung JH, Yu BP. Molecular inflammation as an underlying mechanism of the aging process and age-related diseases. J Dent Res 2011;90:830-840.

14. Evans WJ, Morley JE, Argilés J, Bales C, Baracos V, Guttridge D, Jatoi A, KalantarZadeh K, Lochs H, Mantovani G, Marks D, Mitch WE, Muscaritoli M, Najand A, Ponikowski P, Rossi Fanelli F, Schambelan M, Schols A, Schuster M, Thomas D, Wolfe R, Anker SD. Cachexia: a new definition. Clin Nutr 2008;27:793-799.

15. Derman BA, Macklis JN, Azeem MS, Sayidine S, Basu S, Batus M, Esmail F, Borgia JA, Bonomi P, Fidler MJ. Relationships between longitudinal neutrophil to lymphocyte ratios, body weight changes, and overall survival in patients with non-small cell lung cancer. BMC Cancer 2017;17:141.

16. Gonda $K$, Shibata $M$, Sato $Y$, Washio $M$, Takeshita $H$, Shigeta $H$, Ogura $M$, Oka S, Sakuramoto S. Elevated neutrophil-to-lymphocyte ratio is associated with nutritional impairment, immune suppression, resistance to S-1 plus cisplatin, and poor prognosis in patients with stage IV gastric cancer. Mol Clin Oncol 2017;7:1073-1078.

17. Stoner L, Lucero AA, Palmer BR, Jones LM, Young JM, Faulkner J. Inflammatory biomarkers for predicting cardiovascular disease. Clin Biochem 2013;46:1353-1371

18. Gibson PH, Cuthbertson BH, Croal BL, Rae D, El-Shafei H, Gibson G, Jeffrey $\mathrm{RR}$, Buchan $\mathrm{KG}$, Hillis GS. Usefulness of neutrophil/lymphocyte ratio as predictor of new-onset atrial fibrillation after coronary artery bypass grafting. Am J Cardiol 2010;105:186-191.

19. Gul M, Uyarel H, Ergelen M, Ugur M, Isık T, Ayhan E, Turkkan C, Aksu HU, Akgul 0, Uslu N. Predictive value of neutrophil to lymphocyte ratio in clinical outcomes of non-ST elevation myocardial infarction and unstable angina pectoris: a 3-year follow-up. Clin Appl Thromb Hemost 2014;20:378-384.

20. Bhat $T$, Teli S, Rijal J, Bhat $H$, Raza M, Khoueiry G, Meghani M, Akhtar M, Costantino T. Neutrophil to lymphocyte ratio and cardiovascular diseases: a review. Expert Rev Cardiovasc Ther 2013;11:55-59.

21. Torun S, Tunc BD, Suvak B, Yildiz H, Tas A, Sayilir A, Ozderin YO, Beyazit $Y$, Kayacetin E. Assessment of neutrophil-lymphocyte ratio in ulcerative colitis: a promising marker in predicting disease severity. Clin Res Hepatol Gastroenterol 2012;36:491-497.

22. Öztürk ZA, Kuyumcu ME, Yesil Y, Savas E, Yıldız H, Kepekçi Y, Arıoğul S. Is there a link between neutrophil-lymphocyte ratio and microvascular complications in geriatric diabetic patients? J Endocrinol Invest 2013;36:593-599.

23. Doğrul RT, Varan HD, Kızılarslanoğlu MC, Kılıç MK, Arık G, Kara Ö, Halil M, Cankurtaran M, Yavuz BB. Relationship Between Frailty and Inflammation. Eur J Geriatr Gerontol 2019;1:17-23.

24. Kuyumcu ME, Yesil Y, Oztürk ZA, Kizilarslanoğlu C, Etgül S, Halil M, Ulger Z, Cankurtaran M, Arığul S. The evaluation of neutrophil-lymphocyte ratio in Alzheimer's disease. Dement Geriatr Cogn Disord 2012;34:69-74. 